\title{
Effect of electrochemotherapy with betulinic acid or cisplatin on regulation of heat shock proteins in metastatic human carcinoma cells in vitro
}

\author{
JUSTYNA MĄCZYŃSKA ${ }^{1}$, ANNA CHOROMAŃSKA ${ }^{2}$, JUSTYNA KUTKOWSKA ${ }^{3}$, \\ MAŁGORZATA KOTULSKA ${ }^{4}$, MACIEJ ZALEWSKI ${ }^{5}$, JERZY ZALEWSKI ${ }^{5}$, \\ JULITA KULBACKA $^{6}$ and JOLANTA SACZKO ${ }^{6}$
}

\author{
${ }^{1}$ Division of Radiotherapy and Imaging, Institute of Cancer Research, Sutton SM2 5NG, UK; \\ ${ }^{2}$ Department of Medical Biochemistry, Wroclaw Medical University, 50-368 Wroclaw; \\ ${ }^{3}$ Institute of Immunology and Experimental Therapy, Polish Academy of Sciences, 53-114 Wroclaw; \\ ${ }^{4}$ Institute of Biomedical Engineering and Instrumentation, Wroclaw University of Science and Technology, 50-370 Wroclaw; \\ ${ }^{5}$ Department of Gynecology and Obstetrics, Wroclaw Medical University, 51-618 Wroclaw; \\ ${ }^{6}$ Department of Molecular and Cellular Biology, Faculty of Pharmacy with Division of Laboratory Diagnostics, \\ Wroclaw Medical University, 50-556 Wroclaw, Poland
}

Received August 7, 2018; Accepted April 1, 2019

DOI: 10.3892/or.2019.7103

\begin{abstract}
Betulinic acid (BTA) is naturally occurring triterpene that has received interest as a novel therapeutic substance with cytotoxicity towards a number of cancer cell lines. Despite the wide spectrum of biological and pharmacological effects, its effect may be limited its lipophobic properties. Therefore, strategies to improve the access of BTA to the cells are required to enhance the anticancer effects. Electroporation (EP) enables increased inflow of drugs into cancer cells, even at low doses, which may reduce the side effects caused by high doses of chemotherapy. The potential application of BTA in electrochemotherapy (ECT) in metastatic type of cancers was investigated in the present study. The efficacy of BTA with EP was estimated using a cell survival assay (MTT assay), microscopical morphology analysis and the immunocytochemical
\end{abstract}

Correspondence to: Dr Julita Kulbacka, Department of Molecular and Cellular Biology, Faculty of Pharmacy with Division of Laboratory Diagnostics, Wroclaw Medical University, Borowska 211A, 50-556 Wroclaw, Poland

E-mail: julita.kulbacka@umed.wroc.pl

Dr Justyna Mączyńska, Division of Radiotherapy and Imaging, Institute of Cancer Research, 15 Cotswold Road, Sutton SM2 5NG, UK

E-mail: justynamariapilat@gmail.com

Abbreviations: BTA, betulinic acid; CP, cisplatin; ECT, electrochemotherapy; EP, electroporation; HSP, heat shock protein

Key words: betulinic acid, electroporation, electrochemotherapy, heat shock proteins expression of heat shock proteins (HSPs). HSPs are molecules that protect the cell from harmful environmental, chemical and physical stresses, and ensure cell survival, recovery and proper functioning. HSP expression is induced various stress factors. Therefore, the expression of HSP27 and HSP70 was evaluated after cells were exposed to an external pulsed electric field and anticancer drugs. Facilitated drug delivery and the anticancer effect on metastatic tumor cells were evaluated in vitro. The effect of BTA was compared with cisplatin (CP), a standard cytostatic agent. Two different metastatic cancer cell lines were used, an ovary adenocarcinoma cell line (SW626) and melanoma cell line (Me45). BTA combined with EP exhibited similar efficacy to CP with EP after 24 and $48 \mathrm{~h}$ in SW626 and Me45 cancer cells. Me45 cells also had high HSP27 and low HSP70 immunosignals post-ECT treatment. ECT caused increased expression of HSP27 and HSP70 proteins in SW626 cells, which were less sensitive to ECT than the Me45 melanoma cell line. The results indicate that BTA may be efficiently applied instead of CP in ECT approaches, but its activity differs between tumor cell lines.

\section{Introduction}

Betulinic acid (BTA) is a carboxylic derivative of betulin, a naturally occurring triterpene predominantly found in the birch bark and other plants (1). It exhibits broad-spectrum biological activity even at low concentrations, such as anti-bacterial, anti-inflammatory, anti-herpes simplex virus-1 or anti-malarial (2-4). Previous studies have indicated the potential use of BTA as a new anticancer drug $(5,6)$. It has been reported to induce apoptosis in various human cancer cell lines (7-10). This process occurs independently of the cascades that mediate programed cell death and without the activation of $\mathrm{p} 53$ protein, which is responsible for the promotion of 
apoptosis in cancer cells (11-13). A very important BTA feature is its lack of cytotoxicity against normal cells (14); therefore, it is hypothesized that the use of BTA in cancer treatment may protect patients from the adverse effects of many standard cytostatic drugs (such as cisplatin). However, one of the drawbacks of BTA therapeutic use is its low solubility. One method to overcome this limitation could be structural modification as indicated by several studies $(3,4,15)$. Another solution may be a physical method, such as electroporation, which allows the flow of molecules into the cell.

Electroporation (EP) is a technique that enables the formation of unstable and hydrophilic pores in cell membranes following exposure to high-intensity short electrical pulses that induce the formation of breaks in membranes, through which macromolecules can enter from the intercellular space. In addition, drugs can also penetrate the cell through the pores created by EP. EP has not been fully explored yet. The 'pores' created in EP are unstable, form quickly and disappear within a few seconds to several minutes after the exposure of the cell to the electric field $(16,17)$.

The combination of EP and chemotherapy (CT) is termed electrochemotherapy (ECT). It allows for the delivery of drugs directly into the cell (18). When cytotoxic agents are poorly transported into the cell, the use of ECT enables the passage of cytostatic drugs, enhancing the local treatment of cancer and potentially reducing the side effects of systemic CT by reducing the required doses of drugs. ECT is much faster and more efficient than CT alone, which is crucial for the treatment of patients with cancer. In particular, it may be beneficial for the treatment of drug-resistant tumors in cases when the efficiency of the working dose has been substantially reduced, for example by multidrug resistance mechanisms $(16,18)$. Furthermore, electrical pulses cause decreased blood perfusion in vessels surrounding a tumor and can prolong contact of drugs with cancer cells $(16,19)$. ECT is a very promising method of treatment for superficially located tumors. In some cases, ECT limits the necessity for surgical intervention and saves the organ (19). Currently, in many European countries, bleomycin and cisplatin (CP) are the only cytostatic drugs that are clinically approved for use in ECT protocols $(16,18)$. Therefore, exploration of a less toxic, natural-origin drugs (such as BTA) for use in ECT is highly desirable.

Recent studies have demonstrated that elevated levels of heat shock protein (HSPs), which are ubiquitous intracellular 'stress proteins' or molecular chaperones (20-22), can increase the aggressiveness of cancer, or alter the response to chemoor radiotherapy (23). HSPs are large and heterogeneous molecules involved in a multitude of housekeeping functions within a cell (24-26). Under physiological conditions, HSPs have an important role in stabilizing and maintaining the conformational structure of a protein $(20,25,27)$. Transcription of genes encoding HSPs may be activated by various stimuli, including physical (temperature and radiation), chemical (toxic compounds), and biological factors (cytokines, oxygen-free radicals, and infections) (28). Under cellular stress, HSPs bind to proteins with abnormal structure, thereby preventing the formation of aggregates and allowing the refolding of denatured proteins (25). Additionally, HSPs are indirectly involved in silencing or decreasing the effects of stress factors (20). Among the HSP family, HSP27 and HSP70 are reported to be involved in neoplastic processes, with expression of HSP27 and HSP70 increased in various cancer cell lines (29). These two chaperone proteins inhibit programed cell death, thus supporting tumor development and promoting CT resistance. HSP70 and HSP27 have dual effects on cancer cells; they suppress anticancer mechanisms and also promote the expression of genes responsible for metastases. On the contrary, HSP70 and HSP27 can activate immune pathways that target cancer cells $(30,31)$. HSP70 has an important role in the maintenance of cellular homeostasis. Overexpression of HSP70, and HSP72 in particular, may occur in different types of cancers, Alzheimer disease and various kidney diseases $(28,32)$. HSP27 is member of the small HSP subfamily, associated with a variety of signaling pathways that are critical for cellular functions (33). Among the other roles, small HSPs are involved in the antioxidant defense system within cells (34). HSPs accomplish this via two mechanisms: Indirectly, in which HSPs increase the cellular glutathione level; and directly way, in which HSPs neutralize protein oxidation. Increased expression of HSP27 contributes to resistance to CT and is associated with poor prognosis $(35,36)$. Therefore, HSPs have a potential role in the treatment efficacy among different types of cancers $(23,37,38)$.

ECT is effective in various cutaneous cancer types, including in melanoma treatment, and in cancer of internal organs, such as colorectal metastases (39). Therefore, in the present study, cell lines from melanoma and ovarian metastases of colonic carcinoma were used as a model to investigate the ECT approach in vitro. The aim of this study was to examine the efficacy of BTA as a novel natural-origin compound that can be used for ECT. Cisplatin was also used with EP as the 'gold standard' cytostatic drug. Whether HSPs can be used as biomarkers of the therapeutic effects in cancer cells in the response to stress induced by ECT was also investigated.

\section{Materials and methods}

Cell culture. Two metastatic human cancer cell lines were used, SW626 and Me45. SW626 cells (American Type Culture Collection, Manassas, VA, USA) are derived from an ovarian metastasis of colon adenocarcinoma. Me45 cells are a metastatic human pigmented malignant melanoma cell line was a kind gift from Professor Z. Krawczyk, established in the Department of Experimental and Clinical Radiobiology, Center of Oncology (Gliwice, Poland) (40). Both cell lines were cultured in polystyrene flasks as a monolayer in Dulbecco's modified Eagle's medium (Gibco; Thermo Fisher Scientific, Inc., Waltham, MA, USA) supplemented with $10 \%$ fetal bovine serum (Sigma-Aldrich; Merck KGaA, Darmstadt, Germany) and $50 \mu \mathrm{g} / \mathrm{ml}$ streptomycin (Sigma-Aldrich; Merck KGaA) at $37^{\circ} \mathrm{C}$ in a humidified atmosphere with $5 \% \mathrm{CO}_{2}$. Cells were harvested by trypsinization ( $0.25 \%$ trypsin and $0.02 \%$ EDTA).

MTT cell viability assay. MTT assay (Sigma-Aldrich; Merck $\mathrm{KGaA}$ ) was performed to determine the cell viability. Briefly, $1 \times 10^{4}$ cells/well were seeded into 96-well plates and cultured overnight. The cells were incubated with selected concentrations of drugs $(0-50 \mu \mathrm{M})$ and with or without EP. MTT assay was performed at selected time points after the incubation $(24,48$, and $72 \mathrm{~h}$ ) and according to the 
manufacturer's protocol. Results were determined using a multiwell scanning spectrophotometer at $570 \mathrm{~nm}$ (EnSpire Multimode Plate Reader; PerkinElmer, Inc., Waltham, MA, USA). Cell viability is expressed as normalized percentage of treated cells compared to untreated control cells.

Chemotherapeutic compounds. In this study, two different cytostatic agents were selected. BTA was purchased from Sigma-Aldrich (Merck KGaA), as a naturally derived compound with a potential use in CT, and CP (Sigma-Aldrich; Merck KGaA), as a standard cytostatic drug. Briefly, the cells were incubated with drugs for 24,48 and $72 \mathrm{~h}$ at concentrations ranging from 1-50 $\mu \mathrm{M}$. For further studies, concentrations were selected according to the results obtained from the MTT assay.

EP protocol. EP of cells was performed using an ECM 830 device (BTX; Harvard Apparatus, Holliston, MA, USA). To test the viability of cells following EP, cells were suspended in EP buffer ( $\mathrm{pH} 7.4 ; 10 \mathrm{mM}$ phosphate buffer, $1 \mathrm{mM} \mathrm{MgCl}_{2}$ and $250 \mathrm{mM}$ sucrose) with a low electrical conductivity and placed in cuvettes with parallel electrodes (gap of $4 \mathrm{~mm}$ ). The experiment was performed according to the following selected parameters: A series of eight electric pulses of 800-2,000 V/cm, $100 \mu \mathrm{sec}$ long with $1 \mathrm{sec}$ intervals. Conditions were selected based on previous studies $(41,42)$. After pulsing, the cells were incubated for $10 \mathrm{~min}$ at $37^{\circ} \mathrm{C}$ to enable the resealing of the cell membrane. Subsequently, the cells were tested for viability using the MTT test or by performing immunocytochemical (ICC) analysis. For morphological studies, the cells were seeded on slides 1 day before or were suspended in EP buffer immediately before EP. The adhered cells were electroporated using the Petri Pulser ${ }^{\mathrm{TM}}$ (BTX; Harvard Apparatus) consisting of 13 gold-plated electrodes spaced $2 \mathrm{~mm}$ apart. Microscopic images were collected after a specified time: Immediately $(15 \mathrm{sec})$ or $10 \mathrm{~min}$ after EP, using a camera connected to an inverted microscope (Olympus CX41; Olympus Corporation, Tokyo, Japan).

ECT in vitro. The effect of ECT with CP and BTA in comparison to untreated control cells was analyzed in SW626 and Me45 cancer cell lines. Safe EP parameters and non-cytotoxic concentrations of drugs were selected (50 $\mu \mathrm{M} \mathrm{CP} ; 20 \mu \mathrm{M}$ BTA for Me45 and $1 \mu \mathrm{M}$ BTA for SW626). The cells were prepared for the experiment as described in the EP protocol and were subjected to electric pulses, following suspension in cuvettes containing CP or BTA in EP buffer. After 10 min recovery time at $37^{\circ} \mathrm{C}$, cells were resuspended in culture medium and subjected to the same procedures described in EP protocol.

ICC avidin-biotin complex $(A B C)$ analysis. After CT, EP or ECT cells were plated $\left(2 \times 10^{3}\right)$ into 10 -well microscopic slides (Thermo Fisher Scientific, Inc.). After 24, 48 or $72 \mathrm{~h}$, the cells were fixed with $4 \%$ formalin for $10 \mathrm{~min}$ at room temperature. Blocking was performed using PBS with 5\% fetal bovine serum for $1 \mathrm{~h}$ at room temperature and incubated overnight at $4{ }^{\circ} \mathrm{C}$ with rabbit monoclonal antibodies against HSP27 (G3.1; cat. no. sc-59562) or HSP70 (3A3; cat. no. sc-32239; Santa Cruz Biotechnology, Inc., Dallas, TX, USA) using 1:200 dilution in antibody diluent (EMD Millipore, Billerica, MA,
USA). After $24 \mathrm{~h}$, the slides were incubated with biotinylated secondary anti-rabbit antibody (DAKO LSAB 2 kit; cat. no. K0675; Dako; Agilent Technologies, Inc., Santa Clara, CA, USA) for $30 \mathrm{~min}$ at room temperature. The ICC assay was completed using the peroxidase $\mathrm{ABC}$ method according to the manufacturer's protocol (DAKO LSAB $2 \mathrm{kit}$ ). Briefly, slides were incubated with horseradish peroxidase-conjugated streptavidin for $10 \mathrm{~min}$, followed by $5 \mathrm{~min}$ incubation with diaminobenzidine at room temperature. All slides were counterstained with Mayer's hematoxylin for $1 \mathrm{~min}$ at room temperature (Sigma-Aldrich; Merck KGaA). Blinded samples were analyzed using an upright microscope equipped with a 40 x objective (Olympus BX51; Olympus Corporation). The expression was determined semi-quantitatively by counting the percentage of positively stained cells in randomly selected fields (from a total of 100 cells per sample, with a minimum four fields analyzed). The intensity of staining was evaluated as follows: $(-)$ negative, $(+)$ weak, $(++)$ moderate, and $(+++)$ strong.

Statistical analysis. For the ECT experiments, as there were two factors affecting the proliferation of cells (drug and electric pulses), two-way analysis of variance and Tukey's multiple comparison test in Prism software (v.7.0; GraphPad Software, Inc., La Jolla, CA, USA) was applied to verify the statistical difference between experimental groups. Data are expressed as the mean \pm standard deviation $(n=3)$. $P<0.05$ was considered to indicate a statistically significant difference.

\section{Results}

Cytotoxicity analysis. In Me45 cells, the reduction in cell survival following treatment with $\mathrm{CP}$ and BTA for 24 and 48 h was $\leq 30 \%$ less cells compared with the control group (Fig. 1A and B). Some values were comparable or higher than the control cells. BTA had the most potent negative impact on Me45 cells at concentrations $>10 \mu \mathrm{M}$ for $72 \mathrm{~h}$ (Fig. 1A); at this concentration, BTA caused $\sim 70 \%$ decrease in the cell viability. The cytotoxic activity of $\mathrm{CP}$ (Fig. 1B) was minimal at lower concentrations $(\leq 10 \mu \mathrm{M})$, and a higher decrease $(\sim 35 \%)$ was detected after the longest incubation duration (72 h).

In the SW626 cell line, the low cell viability was obtained after $24 \mathrm{~h}$ incubation with BTA (Fig. 1C). Compared with the control cells, the survival rate was $\sim 15$ and $\sim 20 \%$ following treatment with BTA at 20 and $50 \mu \mathrm{M}$, respectively, for $24 \mathrm{~h}$. After incubation for 48 and $72 \mathrm{~h}$, there was an increase viability of cells compared with $24 \mathrm{~h}$. This indicates that not all cells were affected by BTA and were still able to proliferate. For cells incubated for $72 \mathrm{~h}$ with BTA, the survival rate was $\sim 50 \%$ regardless of the concentration used. SW626 cells exhibited limited sensitivity to CP (Fig. 1D) at all tested concentrations and all time points ( $\leq 30 \%$ reduction in viability).

Effect of EP on cell morphology. The effect of the electrical pulse on SW626 and Me45 cancer cells was observed and recorded using a standard microscope equipped with a camera (Fig. 2). The pores were formed in the cancer cell membrane by stimulation with the high electric field $(1,200 \mathrm{~V} / \mathrm{cm})$. Cytoplasmic outflow was also observed as 'bubbles' at 10 min after EP (Fig. 2C and D). In addition, to 

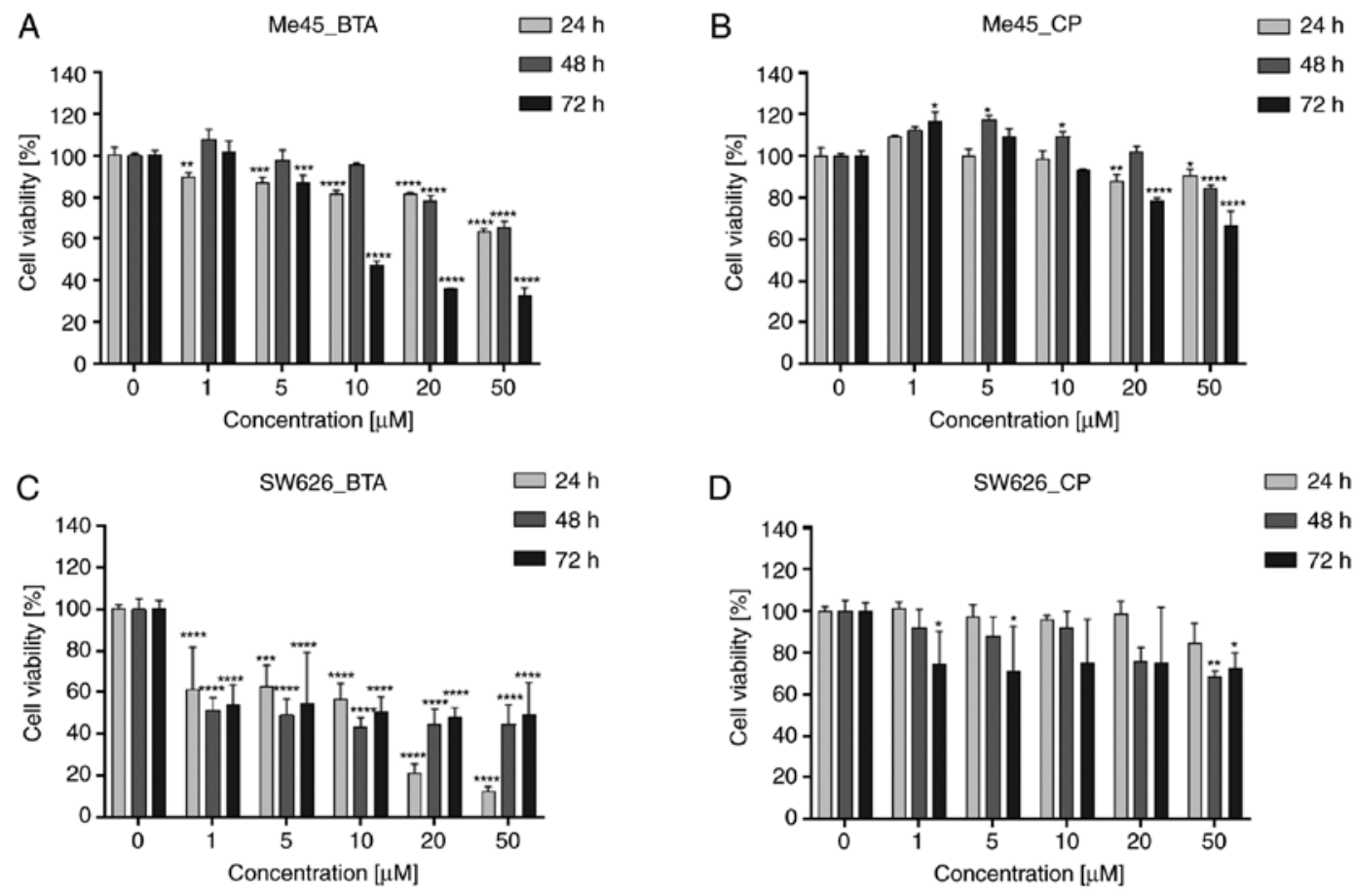

Figure 1. (A and B) Me45 and (C and D) SW626 cell survival rates after 24, 48 and $72 \mathrm{~h}$ of incubation with BTA or CP. Data are presented as the mean \pm standard deviation $(\mathrm{n} \geq 3)$. Statistical significance in comparison with the control groups $(0 \mu \mathrm{M})$ was determined using two-way analysis of variance with Dunnett's multiple comparisons test method. ${ }^{*} \mathrm{P} \leq 0.05 ;{ }^{* *} \mathrm{P} \leq 0.001 ;{ }^{* * *} \mathrm{P} \leq 0.0001 ;{ }^{* * * *} \mathrm{P} \leq 0.00001$ vs. $0 \mu \mathrm{M}$ at each time point. BTA, betulinic acid; CP, cisplatin.

induce and observe visible changes in cell morphology of the cells adhered to the plate after EP, the intensity of the electric field was increased to $3,000 \mathrm{~V} / \mathrm{cm}$ (Fig. 2E and F).

$E C T$. Based on the results of the cytotoxicity and the EP analysis, the effective concentrations of drugs and parameters of EP were selected. Both cell lines were electroporated using the standard parameters ( 8 pulses, $100 \mu$ s pulse duration, $1 \mathrm{~Hz}$ frequency). Two values of electric field strength (800 and 1,200 V/cm) with limited toxic effect were selected for subsequent experiments (Fig. 3). The selection was also based on our previous studies $(43,44)$ and according to standard ECT procedures where the European Standard Operating Procedures of Electrochemotherapy protocol is used. However, the results indicate that selected electric field values had relatively low lethality. Only in melanoma cells was observed a $20 \%$ decrease of cell viability observed after electro-pulsation without any drug. This demonstrated that the selected strengths of the electric field were sufficient for cell permeabilization, enabling the chemotherapeutic agent to enter the cells. Electric field strength $>800 \mathrm{~V} / \mathrm{cm}$ caused a significant decrease in cell viability in both cell lines.

In Me45 cells, $\mathrm{CP}$ at $50 \mu \mathrm{M}$ and BTA at $20 \mu \mathrm{M}$, and three different incubation times $(24,48$ and $72 \mathrm{~h}$ ) were used (Fig. 4A-C). EP at 800 and 1,200 V/cm intensity caused an increase in cell death induced by BTA at 24 and $48 \mathrm{~h}$ (Fig. 4A and B), compared with BTA alone. The presence of $\mathrm{CP}$ in the EP buffer caused a greater reduction in the cell viability than that of BTA in Me45 cells. As the intensity of the electrical pulses increased, there the drug-induced cytotoxicity was increased the Me45 cells. ECT with BTA had a most significant effect than EP or CT alone.
In SW626 cells, two sublethal concentrations of cytostatic drugs (50 $\mu \mathrm{M} \mathrm{CP}$ and $1 \mu \mathrm{M}$ BTA) and three different incubation times (24, 48 and $72 \mathrm{~h}$ ) were used (Fig. 4D-F). According to the results, ECT slightly improved the efficiency of the applied drug. The viability was decreased by $30 \%$ below the level obtained for $\mathrm{CP}$ alone at the same concentration. The $1,200 \mathrm{~V} / \mathrm{cm}$ electric field caused a decrease in the cell viability compared with drug treatment alone after $24 \mathrm{~h}$ (Fig. 4D). No significant increase in the cytotoxic effect of was observed after $48 \mathrm{~h}$. A slight decrease of $\sim 20 \%$ was induced by ECT compared with $\mathrm{CP}$ and BTA alone after $72 \mathrm{~h}$ incubation (Fig. 4E and F).

ICC for HSPs. Various studies have indicated that HSPs have an important role in cancer progression (14). ICC analysis was used to detect expression of the chosen HSPs in the selected cancer cell lines after in vitro CT and ECT. The experiments were conducted with the same parameters as in the previous experiments and were observed using a standard upright microscope. HSPs were visualized with various intensities depending on the cell line. Tables I and II, and Fig. 5 present semi-quantitative values related to the intensities HSP27 and HSP70, and the number of stained cells. For SW626 cells, the highest number of positive cells and the most intense HSP staining (both HSP27 and HSP70) was observed after $72 \mathrm{~h}$ with ECT (Fig. 5B) in particular for CP treatment. In the case of SW626 cells whose appearances exhibited blebbing and affected morphology, HSPs were located inside the nucleus to a considerable extent. The intracellular localization of HSPs was distributed among the cytoplasm and nuclear envelope. The location of both HSPs suggests induction of apoptosis, for example by triggering endogenic apoptosis with the mitochondrial contribution. The relatively high intensity 

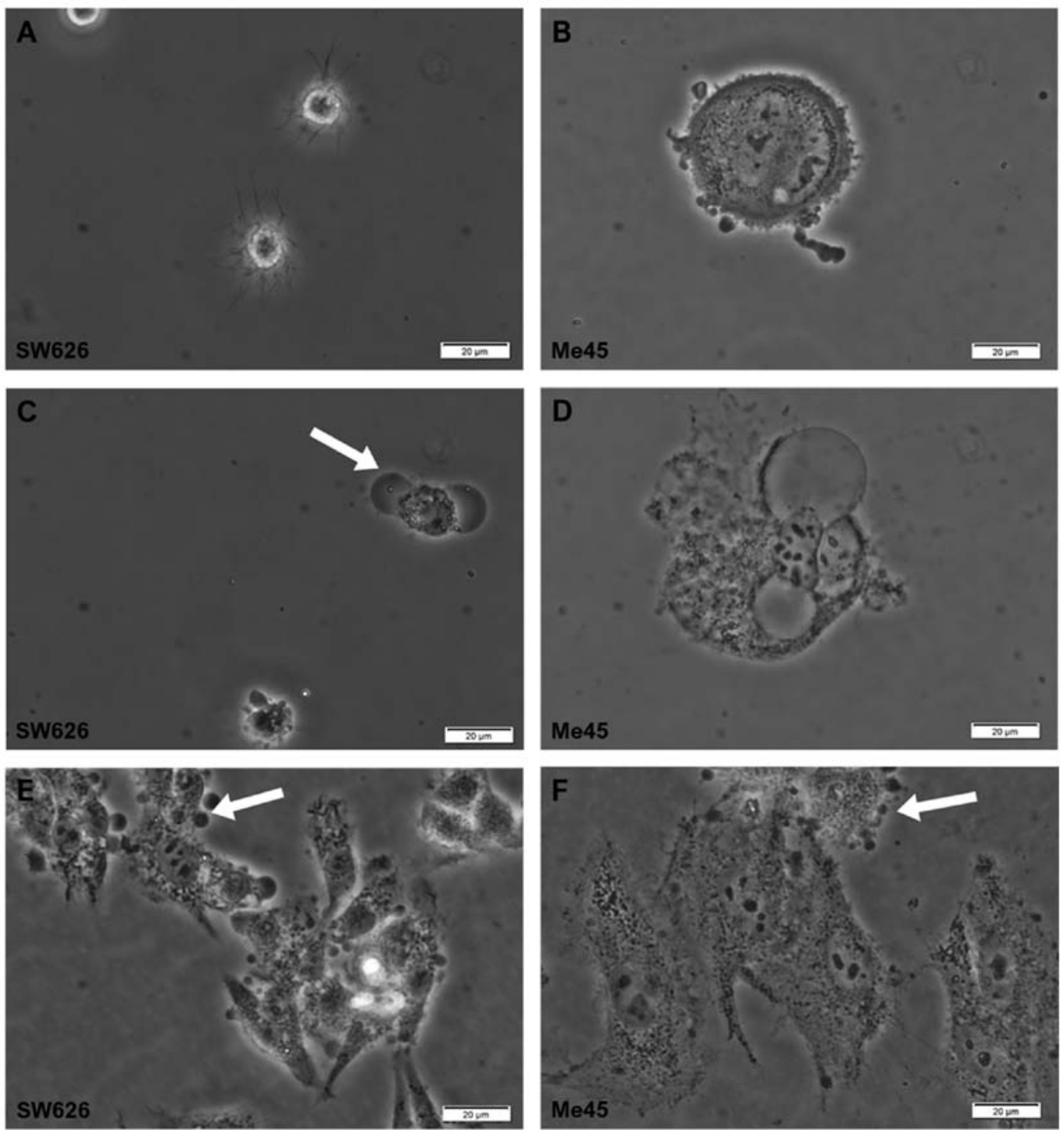

Figure 2. Impact of electroporation on the cell morphology. (A) SW626 cells in suspension $15 \mathrm{sec}$ after electroporation with 1,200 V/cm electric intensity; (B) Me45 cell in suspension $15 \mathrm{sec}$ after electroporation with 1,200 V/cm electric intensity; (C) SW626 cells in suspension $\sim 10$ min after electroporation with 1,200 V/cm electric intensity; (D) Me45 cells in suspension $\sim 10 \mathrm{~min}$ after electroporation with $800 \mathrm{~V} / \mathrm{cm}$ electric intensity; (E) SW626 cells adhered to the substrate after electroporation with 3,000 V/cm electric intensity; (F) Me45 cells adhered to the substrate after electroporation with 2,600 V/cm electric intensity. White arrows indicate characteristic 'bubbles' and cytoplasm outflow.

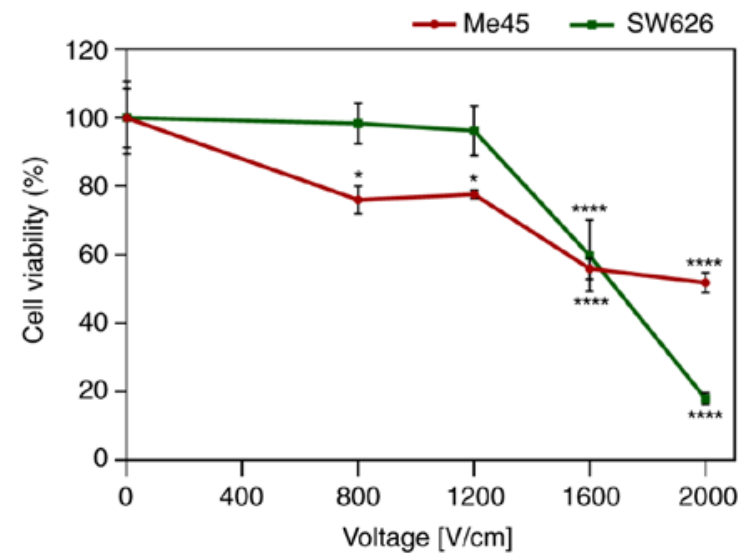

Figure 3. Dependence of SW626 and Me45 cell survival rate on electric field intensity compared with the untreated cells $(0 \mathrm{~V} / \mathrm{cm})$. Data are presented as the mean \pm standard deviation $(\mathrm{n} \geq 3) ;{ }^{*} \mathrm{P} \leq 0.05 ;{ }^{* * * *} \mathrm{P} \leq 0.00001$ vs. $0 \mathrm{~V} / \mathrm{cm}$ as assessed by two-way analysis of variance with Dunnett's multiple comparisons test. of HSPs in numerous SW626 cells was also observed after the exposure of the cells to ECT without BTA or CP (Fig. 5D). In SW626 cells, an intense positive immunoreaction of both HSPs was observed at $24 \mathrm{~h}$ post-ECT with BTA and even more so for $\mathrm{CP}$, which suggests that shock caused by the electric field combined with drug administration had a substantial effect on the expression of HSPs. After $48 \mathrm{~h}$ incubation of ECT treated cells, the amount and intensity of both HSPs considerably decreased, whereas after $72 \mathrm{~h}$ incubation, they were found to be increased again. Melanoma cells also indicated an increased immunostaining in particular after exposition to the strongest electroporation parameters and $72 \mathrm{~h}$ (for EP-BTA and EP-CP), however the reaction was not as strong as in case of SW626 cells. This may result from an individual HSPs level for each cell line.

In Me45 cells, the positive immunoreaction was obtained for HSP27 only (Fig. 5C). The color of the reaction was only visible in cells after ECT (Fig. 5A). In the control and samples 

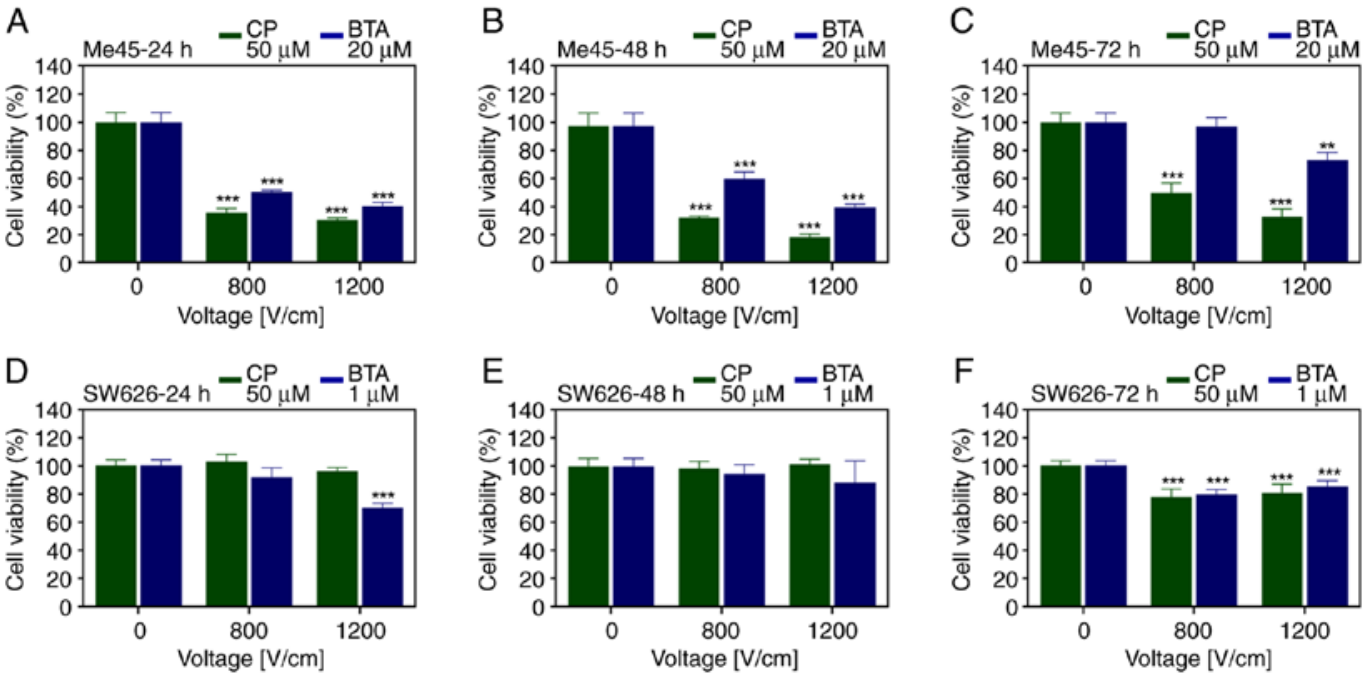

Figure 4. ECT with CP and BTA expressed as a percentage of control cell survival rate in melanoma cells (Me45) after (A) $24 \mathrm{~h}$, (B) $48 \mathrm{~h}$, (C) $72 \mathrm{~h}$, and in ovarian metastatic cells (SW626) after (D) $24 \mathrm{~h}$, (E) $48 \mathrm{~h}$, (F) $72 \mathrm{~h}$ of incubation after ECT. All data are presented as mean \pm standard deviation (n $\geq 6$ ). ${ }^{* * *} \mathrm{P} \leq 0.001 ;{ }^{* * * *} \mathrm{P} \leq 0.0001$ vs. $0 \mathrm{~V} / \mathrm{cm}$. ECT, electrochemotherapy; CP, cisplatin; BTA, betulinic acid.

A
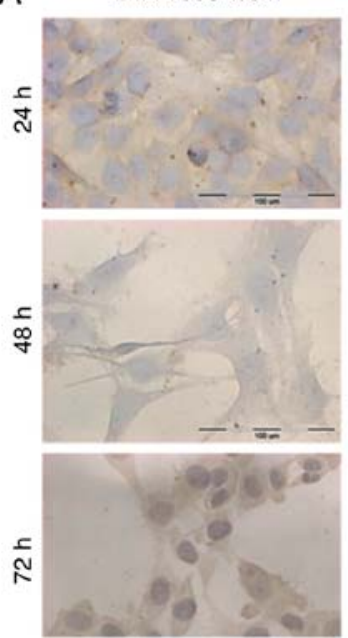

C

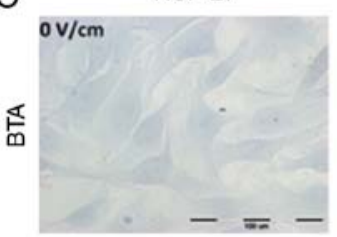

i
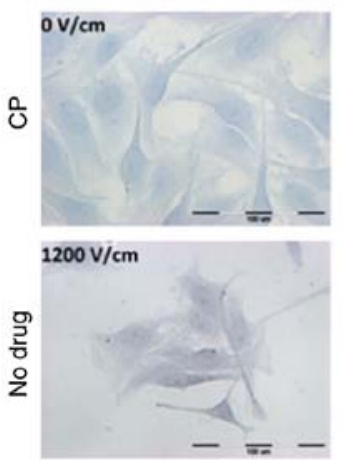

$\mathrm{CP}+800 \mathrm{~V} / \mathrm{cm}$
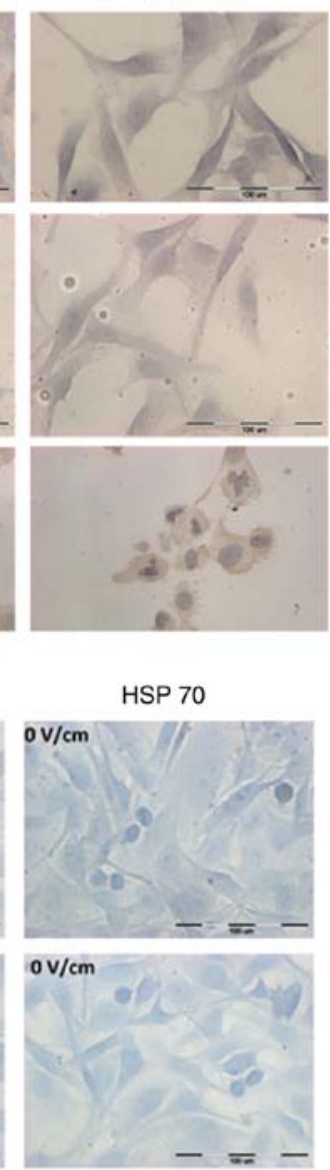

$800 \mathrm{~V} / \mathrm{cm}$
B
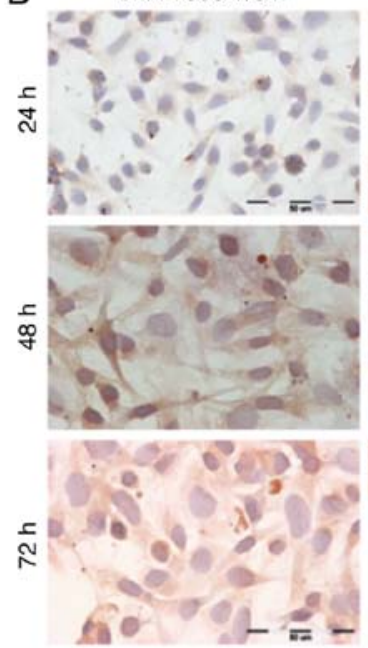

D
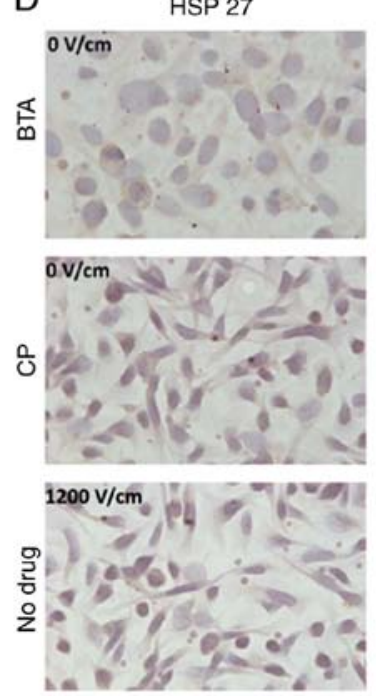

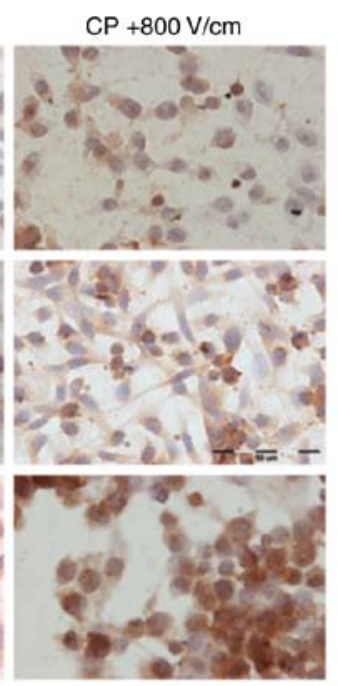

HSP 70
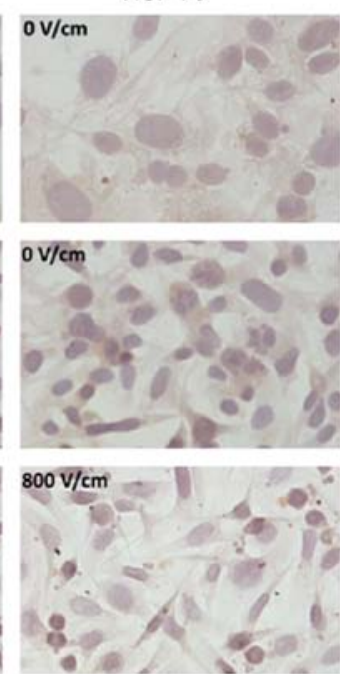

Figure 5. Evaluation of immunocytochemistry reaction with HSP27 antibody in (A) Me45 cells and (B) SW626 cancer cells, after electrochemotherapy with $\mathrm{CP}(50 \mu \mathrm{M})$ or BTA $(50 \mu \mathrm{M})$ combined with pulsed electric field of $800 \mathrm{~V} / \mathrm{cm}$, eight pulses of $100 \mu \mathrm{s}$, after 24,48 and $72 \mathrm{~h}$. Immunoreaction of HSP27 and HSP70 of representative control (C) Me45 cells and (D) SW626 metastatic cells after $48 \mathrm{~h}$. Selected controls represent immunoreaction after exposition to BTA $(20 \mu \mathrm{M}), \mathrm{CP}(50 \mu \mathrm{M})$ or electroporation alone. $\mathrm{CP}$, cisplatin; BTA, betulinic acid. 
Table I. Evaluation of immunocytochemical reaction with HSP27 antibody in SW626 and Me45 cancer cell lines following ECT with CP or BTA.

\section{A, SW626}

\begin{tabular}{|c|c|c|c|c|c|c|c|}
\hline \multirow[b]{2}{*}{ Drug } & \multirow[b]{2}{*}{$\mathrm{EP}(\mathrm{V} / \mathrm{cm})$} & \multicolumn{2}{|c|}{$24 \mathrm{~h}$} & \multicolumn{2}{|c|}{$48 \mathrm{~h}$} & \multicolumn{2}{|c|}{$72 \mathrm{~h}$} \\
\hline & & I & $\%$ & I & $\%$ & I & $\%$ \\
\hline Control cells & 0 & ++ & 99 & & & & \\
\hline \multirow[t]{3}{*}{$\mathrm{CP}(50 \mu \mathrm{M})$} & 0 & ++ & 94 & + & 35 & ++ & 97 \\
\hline & 800 & ++ & 92 & + & 50 & +++ & 100 \\
\hline & 1,200 & ++ & 100 & + & 75 & +++ & 100 \\
\hline \multirow[t]{3}{*}{$\mathrm{BTA}(1 \mu \mathrm{M})$} & 0 & + & 85 & + & 40 & ++ & 98 \\
\hline & 800 & ++ & 90 & + & 80 & +++ & 100 \\
\hline & 1,200 & ++ & 100 & + & 83 & +++ & 100 \\
\hline
\end{tabular}

\section{$\mathrm{B}, \mathrm{Me} 45$}

\begin{tabular}{|c|c|c|c|c|c|c|c|}
\hline \multirow[b]{2}{*}{ Drug } & \multirow[b]{2}{*}{$\mathrm{EP}(\mathrm{V} / \mathrm{cm})$} & \multicolumn{2}{|c|}{$24 \mathrm{~h}$} & \multicolumn{2}{|c|}{$48 \mathrm{~h}$} & \multicolumn{2}{|c|}{$72 \mathrm{~h}$} \\
\hline & & I & $\%$ & I & $\%$ & I & $\%$ \\
\hline Control cells & 0 & - & 0 & - & 0 & - & 0 \\
\hline \multirow[t]{3}{*}{$\mathrm{CP}(50 \mu \mathrm{M})$} & 0 & - & 0 & - & 0 & - & 0 \\
\hline & 800 & +++ & 100 & + & 100 & ++ & 100 \\
\hline & 1,200 & +++ & 100 & + & 100 & ++ & 100 \\
\hline \multirow[t]{3}{*}{$\mathrm{BTA}(20 \mu \mathrm{M})$} & 0 & - & 0 & - & 0 & - & 0 \\
\hline & 800 & +++ & 100 & + & 100 & ++ & 100 \\
\hline & 1,200 & +++ & 100 & + & 100 & ++ & 100 \\
\hline
\end{tabular}

The expression of HSP27 was determined semi-quantitatively by counting percentage of positively stained cells in randomly selected fields (from a total of 100 cells per sample). I was evaluated as: (-) negative, (+) weak, (++) moderate and (+++) strong; \% indicates the percent of positively stained cells. HSP27, heat shock protein 27; ECT, electrochemotherapy; EP, electroporation; BTA, betulinic acid; CP, cisplatin; I, the intensity of reaction.

untreated with EP, there was no positive staining of cells. In addition, after exposure of cells to $1,200 \mathrm{~V} / \mathrm{cm}$ intensity, the cells had shrunk, the cell membrane appeared to lose its continuity and there was an even distribution of HSP27 in the cytoplasm. The intensity of reactions in Me45 cells varied depending on the length of incubation time post-ECT. The most intense HSP27 ICC staining was obtained after $24 \mathrm{~h}$ incubation with $\mathrm{CP}$ and BTA. This indicates a strong protective response in cells caused by environmental stress. After $48 \mathrm{~h}$ of incubation, the staining reaction decreased, and then increased again after $72 \mathrm{~h}$ with BTA and CP.

\section{Discussion}

The results in Me45 cells confirm the utility of EP technique. It significantly enhanced the cytotoxic effect of $\mathrm{CP}$ and to some extent enhanced the effect of BTA. SW626 cells were less susceptible to EP, thus we suppose this cell line may be EP-resistant. ECT-CP exhibited significant and ECT-BTA exhibited a less significant effect at the longest incubation time $(72 \mathrm{~h})$ in Me45 melanoma cells. In the case of the
SW626 metastatic cell line the anticancer effect of ECT was not predominant. Thus, the data confirm that the use of EP is dependent on the tumor type (18).

$\mathrm{CP}$ has been the most effective drug used in the treatment of cancer in the past decades $(41,42)$. Despite this, there are many types of cancers that are resistant to $\mathrm{CP}$ treatment, and this phenomena is not only dependent on drug biodistribution in the cell, but also involves many complex resistance mechanisms $(43,44)$. This was also confirmed by the results of the present study. Both selected cell lines had low sensitivity to treatment with $\mathrm{CP}$ alone, and the viability was maintained in the control level after $24 \mathrm{~h}$. A significant decrease of cell viability was exhibited after 48 and $72 \mathrm{~h}(\sim 30 \%)$ or the highest concentrations. The mechanism of resistance to platinum compounds is achieved by reduced formation of cytotoxic platinum-DNA adducts, decreased drug accumulation, and increased inactivation of the drug by cellular proteins and non-protein thiol groups (41). Numerous studies reported that the use of EP in the treatment of cancer may counterbalance drug resistance phenomena $(16,43,45)$. Previous studies have demonstrated that after ECT with $\mathrm{CP}$, the viability of 
Table II. Evaluation of immunocytochemical reaction with HSP70 antibody in SW626 and Me45 cancer cell lines following ECT with CP or BTA.

\section{A, SW626}

\begin{tabular}{|c|c|c|c|c|c|c|c|}
\hline \multirow[b]{2}{*}{ Drug } & \multirow[b]{2}{*}{$\mathrm{EP}(\mathrm{V} / \mathrm{cm})$} & \multicolumn{2}{|c|}{$24 \mathrm{~h}$} & \multicolumn{2}{|c|}{$48 \mathrm{~h}$} & \multicolumn{2}{|c|}{$72 \mathrm{~h}$} \\
\hline & & I & $\%$ & I & $\%$ & I & $\%$ \\
\hline Control cells & 0 & ++ & 100 & ++ & 100 & ++ & 100 \\
\hline \multirow[t]{3}{*}{$\mathrm{CP}(50 \mu \mathrm{M})$} & 0 & ++ & 98 & + & 55 & ++ & 98 \\
\hline & 800 & ++ & 100 & + & 78 & +++ & 100 \\
\hline & 1,200 & ++ & 100 & + & 81 & ++ & 100 \\
\hline \multirow[t]{3}{*}{ BTA $(1 \mu \mathrm{M})$} & 0 & +++ & 100 & $+/++$ & 56 & $+/++$ & 100 \\
\hline & 800 & ++ & 100 & ++ & 80 & $++/+++$ & 100 \\
\hline & 1,200 & ++ & 100 & ++ & 87 & $++/+++$ & 98 \\
\hline
\end{tabular}

$\mathrm{B}, \mathrm{Me} 45$

\begin{tabular}{|c|c|c|c|c|c|c|c|}
\hline \multirow[b]{2}{*}{ Drug } & \multirow[b]{2}{*}{$\mathrm{EP}(\mathrm{V} / \mathrm{cm})$} & \multicolumn{2}{|l|}{$24 \mathrm{~h}$} & \multicolumn{2}{|c|}{$48 \mathrm{~h}$} & \multicolumn{2}{|c|}{$72 \mathrm{~h}$} \\
\hline & & I & $\%$ & I & $\%$ & I & $\%$ \\
\hline Control cells & 0 & - & 0 & - & 0 & - & 0 \\
\hline \multirow[t]{3}{*}{$\mathrm{CP}(50 \mu \mathrm{M})$} & 0 & - & 0 & - & 0 & - & 0 \\
\hline & 800 & - & 0 & - & 0 & - & 0 \\
\hline & 1,200 & ++ & 97 & ++ & 99 & ++ & 100 \\
\hline \multirow[t]{3}{*}{ BTA $(20 \mu \mathrm{M})$} & 0 & - & 0 & - & 0 & - & 0 \\
\hline & 800 & $+($ pattern distribution $)$ & 9 & + & 98 & ++ & 100 \\
\hline & 1,200 & + & 92 & + & 89 & + & 100 \\
\hline
\end{tabular}

The expression of HSP70 was determined semi-quantitatively by counting percentage of positively stained cells in randomly selected fields (from a total of 100 cells per sample). I was evaluated as: (-) negative, $(+)$ weak, (++) moderate and (+++) strong; \% indicates the percent of positively stained cells. HSP70, heat shock protein 70; ECT, electrochemotherapy; EP, electroporation; BTA, betulinic acid; CP, cisplatin; I, the intensity of reaction.

CP-resistant cells (OvBH-1 and SKOV-3) was decreased significantly compared with CP used alone (46). A recent study has also indicated the advantages of EP in the treatment of neuroblastoma cells, indicating that $\mathrm{CP}$ cytotoxicity was potentiated after exposure of cells to high intensity electric pulses (47). However, certain cell lines remain resistant to CT after EP treatment (48). In the present study, CP alone affected the viability of SW626 cells to a certain extent, and the use of EP significantly supported this effect. Regardless of the use of EP, CP caused a decrease in cell viability by up to $20 \%$, even after $72 \mathrm{~h}$ incubation.

BTA has been reported to decrease the growth and survival rate of several types of cancer $(49,50)$. The effect is associated with the ability of BTA to induce programed cell death in tumor cells by triggering the mitochondrial apoptotic pathway and inhibition of multiple pro-oncogenic factors $(13,51,52)$. The present study is the first to use BTA in ECT, which may overcome difficulty in BTA penetration through cells membranes. The effect of BTA in ECT was evaluated in two cell lines. In Me45 cells, the application of electrical pulses significantly increased the cytotoxic effect of BTA. Experiments on SW626 cells also confirmed the anticancer properties of BTA at low concentrations using EP, and significantly reduced cell survival, but with less effect than in melanoma cells. A closer examination on the effect of EP on the compound itself may be crucial. The data confirms the differences in ECT sensitivities between the two cell lines (53). One of the strategies to increase hydrosolubility and improve the anticancer properties of BTA is to use derivatives or analogs of BTA (e.g. with a triazole group added) (54). Another method to increase the toxic effect on cancer cells may be combination therapy. In recent studies, it was proposed that combining BTA with different active compounds, such as gemcitabine (55) or sorafenib (56), may increases the anticancer effects. In certain of these cases, the application of EP with CP may reduce the dose of drugs, which may minimize side effects.

HSPs expression in cells subjected to ECT does not clearly indicate whether a tumor cells will enter the apoptotic pathway or protect themselves. Despite this, HSP27 was detected in both cell lines following ECT. Upregulation of HSP27 has 
been reported in multiple types of malignancy, including ovarian carcinoma and melanoma. Along HSPs have been implicated in oncogenesis and CT resistance (36). The presence of HSP27 indicates activation of anti-apoptotic defense mechanisms, whereas the lack of HSP70 suggests the opposite. The current results indicate that EP enhanced HSP27 in both cell lines at all time point, but HSP70 only in SW626 cells. Other researchers have also demonstrated that EP induces the expression of HSP70 to a certain extent, as a result of environmental stress (57). However, another study demonstrated HSP70 induction may depend on the cell line (58). The data of the present study indicate that chemotherapeutic protocols may modulate expression of HSP27 and HSP70 in tumor tissues. Vargas-Roig et al (59) observed that after chemotherapy, nuclear HSP27 and HSP70 expression was increased, and HSP70 and heat shock cognate 70 cytoplasmic expression decreased in patients with breast cancer (59). Arts et al (60) reported that HSP27 expression was negative before and positive after chemotherapy in only $2 / 30$ paired samples, whereas hsp27 expression was positive before and negative after chemotherapy in 5/30 samples. In general, elevated levels of HSPs are associated with drug resistance and poor prognosis (61). Therefore, the presence of these two proteins (HSP27 and HSP70) in untreated SW626 cells indicates higher resistance to the applied treatment. Untreated Me45 cells did not express HSPs; thus, they were more sensitive to ECT. This indicates stronger intracellular defense mechanisms of ovarian cancer cells.

Additionally, different cell lines may exhibit variation in their tolerance to electric fields. The effect of electric pulses depends on the size, density and shape of the cell (62). A recent study also reported the differences between cell lines in the kinetics of membrane resealing; this process determines how fast the electropores in membranes are closed following exposure to electric pulses (63). It has been reported that pores in the membrane of various tumor malignant cell lines reseal much faster (up to 300\%) than in normal cell lines. Furthermore, a strong correlation between the resealing response of cancer cells and their resistance to standard drugs, such as CP, was reported. These properties may enhance or limit the efficiency of EP in cancer cells. Thus, further studies are required to assess the efficiency of this treatment modality.

In summary, the present findings indicate that ECT protocols are highly variable depending on the type of cancer cells. Ovarian metastatic SW626 cells were marginally more sensitive to standard therapy with CP then Me45 melanoma cells. Additionally, BTA, a natural compound, exhibited potent cytotoxic effects in SW626 cells. The application of EP enhanced the effects of BTA in Me45 melanoma cells, and may applied instead of CP. The next stages of research should focus on further characterization of the action of BTA on tumor cells. Furthermore, as therapies with natural compounds appears to be safe and cause less side effects than standard cytostatics, further research will aim to expand the pool of test compounds with anticancer properties that can be enhanced by EP.

\section{Acknowledgements}

Not applicable.

\section{Funding}

The present study was supported by the Wroclaw Medical University Statutory Funds ST.E130.16.060 (PI: M. Zalewski).

\section{Availability of data and materials}

The datasets used in this study are available from the corresponding author upon reasonable request.

\section{Authors' contributions}

JS, MK, JZ, MZ, JM and JK participated in the design of the study, data interpretation, and manuscript drafting. JM, JKut, and ACh performed the experiments. All authors read and approved the manuscript and agree to be accountable for all aspects of the research in ensuring that the accuracy or integrity of any part of the work are appropriately investigated and resolved.

\section{Ethics approval and consent to participate}

Not applicable.

\section{Patient consent for publication}

Not applicable.

\section{Competing interests}

The authors declare that they have no competing interests.

\section{References}

1. Fulda S: Betulinic acid for cancer treatment and prevention. Int $\mathbf{J}$ Mol Sci 9: 1096-1107, 2008.

2. Osunsanmi FO, Shode FO and Opoku AR: Anti-inflammatory activity of betulinic acid and its acetyl derivative from melaleuca bracteata. S Afr J Bot 103: 342-342, 2016. http://dx.doi.org/10.4314/ tipr.v17i10.13

3. Pavlova NI, Savinova OV, Nikolaeva SN, Boreko EI and Flekhter OB: Antiviral activity of betulin, betulinic and betulonic acids against some enveloped and non-enveloped viruses. Fitoterapia 74: 489-492, 2003.

4. Bringmann G, Saeb W, Assi LA, François G, Sankara Narayanan AS, Peters K and Peters EM: Betulinic acid: Isolation from Triphyophyllum peltatum and Ancistrocladus heyneanus, antimalarial activity, and crystal structure of the benzyl ester. Planta Med 63: 255-257, 1997.

5. Damle AA, Pawar YP and Narkar AA: Anticancer activity of betulinic acid on MCF-7 tumors in nude mice. Indian J Exp Biol 51: 485-491, 2013.

6. Eiznhamer DA and Xu ZQ: Betulinic acid: A promising anticancer candidate. IDrugs 7: 359-373, 2004.

7. Rzeski W, Stepulak A, Szymański M, Sifringer M, Kaczor J, Wejksza K, Zdzisińska B and Kandefer-Szerszeń M: Betulinic acid decreases expression of bcl-2 and cyclin D1, inhibits proliferation, migration and induces apoptosis in cancer cells. Naunyn Schmiedebergs Arch Pharmacol 374: 11-20, 2006.

8. Ehrhardt H, Fulda S, Fuhrer M, Debatin KM and Jeremias I: Betulinic acid-induced apoptosis in leukemia cells. Leukemia 18: 1406-1412, 2004

9. Schmidt ML, Kuzmanoff KL, Ling-Indeck L and Pezzuto JM: Betulinic acid induces apoptosis in human neuroblastoma cell lines. Eur J Cancer 33: 2007-2010, 1997.

10. Chintharlapalli S, Papineni S, Ramaiah SK and Safe S: Betulinic acid inhibits prostate cancer growth through inhibition of specificity protein transcription factors. Cancer Res 67: 2816-2823, 2007. 
11. Drag-Zalesinska M, Kulbacka J, Saczko J, Wysocka T, Zabel M, Surowiak P and Drag M: Esters of betulin and betulinic acid with amino acids have improved water solubility and are selectively cytotoxic toward cancer cells. Bioorg Med Chem Lett 19: 4814-4817, 2009.

12. Pisha E, Chai H, Lee IS, Chagwedera TE, Farnsworth NR, Cordell GA, Beecher CW, Fong HH, Kinghorn AD and Brown DM: Discovery of betulinic acid as a selective inhibitor of human-melanoma that functions by induction of apoptosis. Nat Med 1: 1046-1051, 1995.

13. Fulda $\mathrm{S}$ and Kroemer G: Targeting mitochondrial apoptosis by betulinic acid in human cancers. Drug Discov Today 14 885-890, 2009

14. Cichewicz RH and Kouzi SA: Chemistry, biological activity, and chemotherapeutic potential of betulinic acid for the prevention and treatment of cancer and HIV infection. Med Res Rev 24 90-114, 2004

15. Bache M, Bernhardt S, Passin S, Wichmann H, Hein A, Zschornak M, Kappler M, Taubert H, Paschke R and Vordermark D: Betulinic acid derivatives NVX-207 and B10 for treatment of glioblastoma-an in vitro study of cytotoxicity and radiosensitization. Int J Mol Sci 15: 19777-19790, 2014.

16. Skolucka N, Saczko J, Kotulska M, Kulbacka J and Choromanska A: Electroporation and its application. Pol Merkur Lekarski 28: 501-504, 2010 (In Polish).

17. Kotulska M, Kubica K, Koronkiewicz S and Kalinowski S Modeling the induction of lipid membrane electropermeabilization. Bioelectrochemistry 70: 64-70, 2007.

18. Sersa G, Miklavcic D, Cemazar M, Rudolf Z, Pucihar G and Snoj M: Electrochemotherapy in treatment of tumours. Eur J Surg Oncol 34: 232-240, 2008

19. Kotulska M: Electrochemotherapy in cancer treatment. Adv Clin Exp Med 16: 601-607, 2007.

20. Kazmierczuk A and Kilianska ZM: The pleiotropic activity of heat-shock proteins. Postepy Hig Med Dosw (Online) 63 502-521, 2009 (In Polish).

21. Schlesinger MJ: Heat-shock proteins-the search for functions. J Cell Biol 103: 321-325, 1986.

22. Cymerys $\mathbf{J}$ and Niemialkowski M: Heat-shock-proteinsmolecular-perpetual-motion. Post Biol Kom 31: 332-339, 2004.

23. Kaigorodova EV and Bogatyuk MV: Heat shock proteins as prognostic markers of cancer. Curr Cancer Drug Targets 14: 713-726, 2014

24. Kulczynska A, Kostur A and Piszcz J: Heat shock proteins in the pathogenesis and treatment of cancer. Acta Haematol Pol 41: 253-259, 2010. pthit.pl/download,ahp,538

25. Kazmierczuk A and Kilianska ZM: Role of heat shock proteins in cell apoptosis. Postepy Hig Med Dosw (Online) 64: 273-283, 2010 (In Polish).

26. Liberek K, Lewandowska A and Zietkiewicz S: Chaperones in control of protein disaggregation. EMBO J 27: 328-335, 2008.

27. Verbeke P, Fonager J, Clark BF and Rattan SI: Heat shock response and ageing: Mechanisms and applications. Cell Biol Int 25: 845-857, 2001

28. Musial K and Zwolinska D: Heat shock proteins in chronic kidney disease. Pediatr Nephrol 26: 1031-1037, 2011.

29. Garrido C, Schmitt E, Cande C, Vahsen N, Parcellier A and Kroemer G: HSP27 and HSP70: potentially oncogenic apoptosis inhibitors. Cell Cycle 2: 579-584, 2003

30. Calderwood SK: Heat shock proteins and cancer: Intracellular chaperones or extracellular signalling ligands?. Philos Trans R Soc Lond B Biol Sci 373: 20160524, 2018.

31. Lee CT and Repasky EA: Opposing roles for heat and heat shock proteins in macrophage functions during inflammation: A function of cell activation state? Front Immunol 3: 140, 2012.

32. Wang H, Tan MS, Lu RC, Yu JT and Tan L: Heat shock proteins at the crossroads between cancer and Alzheimer's disease. Biomed Res Int 2014: 239164, 2014.

33. Vidyasagar A, Wilson NA and Djamali A: Heat shock protein 27 (HSP27): Biomarker of disease and therapeutic target. Fibrogenesis Tissue Repair 5: 7, 2012.

34. Tian X, Zhao L, Song X, Yan Y, Liu N, Li T, Yan B and Liu B: HSP27 inhibits homocysteine-induced endothelial apoptosis by modulation of ROS production and mitochondrial caspase-dependent apoptotic pathway. Biomed Res Int 2016: 4847874, 2016.
35. Zheng G, Zhang Z, Liu H, Xiong Y, Luo L, Jia X, Peng C, Zhang Q, Li N, Gu Y, et al: HSP27-mediated extracellular and intracellular signaling pathways synergistically confer chemo-resistance in squamous cell carcinoma of tongue. Clin Cancer Res 24: 1163-1175, 2018.

36. Zhang Y and Shen X: Heat shock protein 27 protects L929 cells from cisplatin-induced apoptosis by enhancing akt activation and abating suppression of thioredoxin reductase activity. Clin Canc Res 13: 2855-2864, 2007

37. Wang XP, Wang QX, Lin HP, Xu B, Zhao Q and Chen K: Recombinant heat shock protein 70 functional peptide and alpha-fetoprotein epitope peptide vaccine elicits specific anti-tumor immunity. Oncotarget 7: 71274-71284, 2016.

38. Shevtsov M and Multhoff G: Heat shock protein-peptide and HSP-based immunotherapies for the treatment of cancer. Front Immunol 7: 171, 2016.

39. Edhemovic I, Brecelj E, Gasljevic G, Marolt Music M, Gorjup V, Mali B, Jarm T, Kos B, Pavliha D, Grcar Kuzmanov B, Cemazar M, et al: Intraoperative electrochemotherapy of colorectal liver metastases. J Surg Oncol 110: 320-327, 2014.

40. Kumala S, Niemiec $P$, Widel $M$, Hancock $R$ and Rzeszowska-Wolny J: Apoptosis and clonogenic cell survival in three tumour cell lines exposed to gamma rays or chemical genotoxic agents. Cell Mol Biol Lett 8: 655-665, 2003

41. Helm CW and States JC: Enhancing the efficacy of cisplatin in ovarian cancer treatment-could arsenic have a role. J Ovarian Res 2: 2, 2009

42. Galluzzi L, Vitale I, Michels J, Brenner C, Szabadkai G, Harel-Bellan A, Castedo M and Kroemer G: Systems biology of cisplatin resistance: Past, present and future. Cell Death Dis 5: e1257, 2014

43. Wezgowiec J, Kulbacka J, Saczko J, Rossowska J, Chodaczek G and Kotulska M: Biological effects in photodynamic treatment combined with electropermeabilization in wild and drug resistant breast cancer cells. Bioelectrochemistry 123: 9-18, 2018.

44. Michel O, Kulbacka J, Saczko J, Mączyńska J, Błasiak P, Rossowska J and Rzechonek A: Electroporation with cisplatin against metastatic pancreatic cancer: In vitro study on human primary cell culture. BioMed Res Int 2018: 7364539, 2018.

45. Gothelf A, Mir LM and Gehl J: Electrochemotherapy: Results of cancer treatment using enhanced delivery of bleomycin by electroporation. Cancer Treat Rev 29: 371-387, 2003.

46. Saczko J, Kamińska I, Kotulska M, Bar J, Choromańska A, Rembiałkowska N, Bieżuńska-Kusiak K, Rossowska J, Nowakowska D and Kulbacka J: Combination of therapy with 5 -fluorouracil and cisplatin with electroporation in human ovarian carcinoma model in vitro. Biomed Pharmacother 68: 573-580, 2014.

47. Esmekaya MA, Kayhan H, Coskun A and Canseven AG: Effects of cisplatin electrochemotherapy on human neuroblastoma cells. J Membr Biol 249: 601-610, 2016.

48. Cemazar M, Sersa G and Miklavcic D: Electrochemotherapy with cisplatin in the treatment of tumor cells resistant to cisplatin. Anticancer Res 18: 4463-4466, 1998.

49. Zhao J, Li R, Pawlak A, Henklewska M, Sysak A, Wen L, Yi JE and Obmińska-Mrukowicz B: Antitumor activity of betulinic acid and betulin in canine cancer cell lines. In Vivo 32: 1081-1088, 2018

50. Xu J, Wang X, Zhang H, Yue J, Sun Y, Zhang X and Zhao Y: Synthesis of triterpenoid derivatives and their anti-tumor and anti-hepatic fibrosis activities. Nat Prod Res 16: 1-7, 2018.

51. Chintharlapalli S, Papineni S, Lei P, Pathi S and Safe S: Betulinic acid inhibits colon cancer cell and tumor growth and induces proteasome-dependent and -independent downregulation of specificity proteins $(\mathrm{Sp})$ transcription factors. BMC Cancer 11: 371, 2011

52. Sun L, Cao J, Chen K, Cheng L, Zhou C, Yan B, Qian W, Li J, Duan W, Ma J, et al: Betulinic acid inhibits stemness and EMT of pancreatic cancer cells via activation of AMPK signaling. Int J Oncol 54: 98-110, 2019.

53. Periasamy G, Teketelew G, Gebrelibanos M, Sintayehu B, Gebrehiwot M, Karim A and Geremedhin G: Betulinic acid and its derivatives as anti-cancer agent: A review. Arch Appl Sci Res 6: 47-58, 2014.

54. Yang S, Liang N, Li H, Xue W, Hu D, Jin L, Zhao Q and Yang S: Design, synthesis and biological evaluation of novel betulinic acid derivatives. Chem Cent J 6: 141, 2012. 
55. Pandita A, Kumar B, Manvati S, Vaishnavi S, Singh SK and Bamezai RN: Synergistic combination of gemcitabine and dietary molecule induces apoptosis in pancreatic cancer cells and down regulates PKM2 expression. PLoS One 9: e107154, 2014.

56. Kutkowska J, Strzadala L and Rapak A: Sorafenib in combination with betulinic acid synergistically induces cell cycle arrest and inhibits clonogenic activity in pancreatic ductal adenocarcinoma cells. Int J Mol Sci 19: E3234, 2018

57. Mlakar V, Todorovic V, Cemazar M, Glavac D and Sersa G: Electric pulses used in electrochemotherapy and electrogene therapy do not significantly change the expression profile of genes involved in the development of cancer in malignant melanoma cells. BMC Cancer 9: 299, 2009.

58. Dressel R, Baraki H, Langer F and Gunther E: Reduced susceptibility of electroporated tumor cell lines to killing by cytotoxic lymphocytes. Biochem Biophys Res Commun 250: 259-263, 1998.

59. Vargas-Roig LM, Gago FE, Tello O, Aznar JC and Ciocca DR: Heat shock protein expression and drug resistance in breast cancer patients treated with induction chemotherapy. Int J Cancer 79: 468-475, 1998.
60. Arts HJ, Hollema H, Lemstra W, Willemse PH, De Vries EG, KampingaHHand VanderZee AG: Heat-shock-protein-27 (hsp27) expression in ovarian carcinoma: Relation in response to chemotherapy and prognosis. Int J Cancer 84: 234-238, 1999.

61. Tóth ME, Gombos I and Sántha M: Heat shock proteins and their role in human diseases. Acta Biol Szeged 59: 121-141, 2015. https://www2.sci.u-szeged.hu/ABS/2015/Acta\%20HPb/59121.pdf

62. Talele S and Gaynor P: Non-linear time domain model of electropermeabilization: Effect of extracellular conductivity and applied electric field parameters. J Electrost 66: 328-334, 2008. https://doi.org/10.1016/j.elstat.2008.02.002

63. Hui TH, Zhou ZL, Fong HW, Ngan RK, Lee TY, Au JS, Ngan AH, Yip TT and Lin Y: Characterizing the malignancy and drug resistance of cancer cells from their membrane resealing response. Sci Rep 6: 26692, 2016. 